\title{
PREFERÊNCIA DA PAISAGEM NO PARQUE MUNICIPAL RUDOLFO ARNO GOLDHARDT DE PANAMBI/RS
}

\section{LANDSCAPE PREFERENCE IN THE "MUNICIPAL PARK RUDOLFO ARNO GOLDHARDT" OF PANAMBI/RS}

\author{
Samara Simon Christmann \\ Eliane Maria Foleto
}

\section{Resumo}

O presente artigo busca analisar um dos principais espaços livres dedicados ao lazer e recreação da população de Panambi/RS: o Parque Municipal Rudolfo Arno Goldhardt. Procura-se avaliá-lo por meio da preferência da paisagem - que pode ser replicado em outros espaços livres -, através de fotografias e questionários de abordagem quali-quantitativa que exploram a percepção e opinião da população. Ao final procura-se contribuir com recomendações que subsidiem na sua gestão e planejamento territorial, com o objetivo de valorizar as potencialidades locais, investir nas fragilidades, possibilitar melhor apropriação e identidade e promover a conservação ambiental.

Palavras-chave: Espaços livres. Preferência da Paisagem. Questionários. Parques.

\section{Abstract}

The present article aims to analyze one of the main open spaces dedicated to leisure and recreation of the population of Panambi / RS: the Municipal Park Rudolfo Arno Goldhardt. It is sought to evaluate it through landscape preference - which can be replicated in other open spaces through photographs and questionnaires with a qualitative-quantitative approach that explore the perception and opinion of the population. At the end, it seeks to contribute with recommendations that subsidize in its management and territorial planning, in the areas of valorizing local potentialities, investing in fragilities, enabling better ownership and identity, and promoting environmental conservation.

Keywords: Open spaces. Landscape Preference. Questionnaires. Parks. 


\section{InTROduÇão}

Parques urbanos são elementos da paisagem urbana que permeiam o espaço construído, constituído por um território específico. Eles são considerados espaços livres de lazer e equipamentos públicos, além de símbolos da arquitetura da cidade moderna com ideais que se propagam para a contemporaneidade. Um de seus objetivos é atender ao maior número de pessoas, e por isso notavelmente, agregam o maior programa de atividades possível, fator que o diferencia das praças além do caráter de extensão/área.

Assim, pode-se definir o parque como "um espaço livre público estruturado por vegetação e dedicado ao lazer da massa urbana" (MACEDO; SAKATA, 2010, p. 13), independente do seu tipo (ecológico, temático, urbano, etc.), e que incorpore intenções de conservação. E, quanto a sua área superficial, pode abranger vários portes, sendo que o parque urbano é envolvido pelo tecido 列 setores (MASCARÓ, 2008).

De acordo com Macedo et al. (2009), os parques se tornaram um dos principais espaços de lazer de fim de semana de grandes contingentes da população, com expansão significativa em todo o país. Neste sentido, estes ambientes se constituem paisagem e unidades urbanísticas, que buscam promover a sociabilidade (encontro, circulação, permanência, descanso), apreciação cênica, seu uso e conservação, exaltar potenciais ambientais, construir uma identidade local, contato com áreas verdes, qualidade ambiental e de vida para a população.

Desta forma, espaço livre intraurbano pode ser definido por todas as áreas não contidas por edifícios de moradia e trabalho ou destinado a algum tipo de uso urbano ao ar livre, de caráte público ou privado, e que configura espaços dentro do tecido urbano, como as ruas, pátios, estacionamentos descobertos, jardins, terrenos baldios, largos, praças, parques, rios, lagos, campos, bosques, florestas, vazios urbanos, etc. (MAGNOLI, 1982; MACEDO, 1995; MACEDO; ROBBA, 2002).
Logo, ao se ter consciência da importância dos espaços livres de lazer e recreação para os cidadãos e cidades, questionou-se sobre as características físico-ambientais do Parque Municipal Rudolfo Arno Goldhart de Panambi/RS, bem como, os seus padrões de uso/atividades, a percepção da população em relação ao espaço livre, e as necessidades da maior parte dos usuários em termos de lazer e recreação.

Deste modo, esta pesquisa - que integra parte da dissertação "Espaços livres de lazer e recreação de Panambi/RS: da análise e percepção à gestão da paisagem", do Programa de Pós-Graduação em Geografia da UFSM, em nível de mestrado - teve como objetivo analisar o Parque Municipal de Panambi/RS, ao considerar os seus aspectos físico-ambientais (recursos naturais, estruturas físicas, mobiliário urbano e infraestrutura), características, funcionalidades, e formas de uso, além de avaliá-lo por meio da preferência da paisagem, através da percepção e opinião da população, e contribuir com diretrizes/recomendações que subsidiem a gestão e planejamento territorial de futuras intervenções e manutenção.

\section{Preferência da Paisagem}

A percepção da paisagem coloca sob um mesmo rótulo as diferentes perspectivas do estudo ambiente-comportamento, principalmente nas áreas de geografia e arquitetura. Neste sentido, os estudos da relação entre o homem e o ambiente, por meio de processos mentais, são denominados de cognição ambiental, em que a percepção é uma dessas etapas (PEREIRA, 2012), e será resultante da associação do ambiente físico com o ambiente percebido (de acordo com as experiências individuais).

Deste modo, a percepção advém desse contato sensorial, com uma ação direta e uma resposta imediata em relação à preferência, e há uma avaliação do espaço vislumbrado e suas qualidades (KAPLAN, 1985), que pode ser externalizada/transmitida de forma positiva ou negativa. Portanto, a percepção é subjetiva, pois se condiciona a fatores particulares de cada indivíduo, a fatores educativos e culturais, e fatores emotivos, afetivos e sensitivos, 
derivados das relações do observador com o ambiente (BIONDI, KOZERA, VIEIRA, 2007, p. 422).

Nesta concepção subjetivista, destaca-se a importância para o planejamento ambiental ao se considerar a percepção como um elemento importante de representação social da população sobre seu entorno. Assim, poderá se compreender como a sociedade concebe, percebe e transforma a natureza, por meio das suas atividades, usos, significados e identidade. Porque, conforme Veras (1995) apud Rodriguez e Silva (2013), essa imagem mental se reflete no uso e gestão do seu espaço, paisagem e território.

Neste sentido, de acordo com Bernáldez (1985), o estudo da percepção tem uma grande importância, pois permite compreender fenômenos culturais, interpretar o simbolismo no entorno urbano, mas também, a reconhecer os recursos naturais e o patrimônio que eles podem representar. Além disso, tais pesquisas são necessárias para atualizar os usos que são atribuídos a uma paisagem, os seus recursos, e principalmente, propiciar um desenvolvimento equilibrado deles.

Desta forma, sob uma perspectiva empírica e sensorial de valorização da experiência dos indivíduos em relação a uma paisagem, que busca compreender a percepção dos mesmos, destaca-se aqui o estudo da preferência da paisagem. Ele geralmente é um exercício comparativo que leva em consideração a sensibilidade e percepção humana, de ordem estética e psicológica, para compreender as preferências e relações entre uma ou várias paisagens e o homem (BOLÓS, 1992).

Ou seja, conforme Karjalainen (2006) apud André, Schwarz e Sevegnani (2008), o termo preferência é utilizado no estudo de paisagens, que evidencia o gosto, simpatia e apreciação das pessoas pela paisagem. Para Tuan (1975), além das paisagens refletirem as preferências de seus observadores, evoca os seus sentimentos, tais como acolhimento, tranquilidade, insegurança ou medo.

Kaplan (1985) cita que nesses tipos de pesquisa, existem implicações dos resultados na arquitetura paisagística, tal como o arranjo dos elementos construídos ou naturais no espaço, que é um fator central da preferência humana, e que poderá resultar em alterações da paisagem. Porém, deve haver cuidado para que esse conjunto de conhecimento obtido possa ajudar na tomada de decisões, na gestão e planejamento. Para isso, é necessário considerar respostas da participação pública com as características e opiniões particularmente mais ressaltadas e importantes da paisagem, perguntando quais os seus usos e aspectos positivos e negativos (KAPLAN, 1985).

Logo, a análise de preferências de uma paisagem pode fornecer parâmetros para a gestão sobre um território, definir prioridades de ação ou conservação, e também subsidiar estratégias de interpretação e sensibilização sobre ele. Por isso, conforme Pereira (2012), a preferência da paisagem se constitui de processos avaliativos afetivos interpretativos e valorativos, que são de suma importância para a avaliação ambiental. Além de que

Nos estudos de percepção ambiental os julgamentos estéticos, por simulação de imagem de paisagens, podem fornecer uma medida adequada da qualidade da paisagem [...]. Nesse sentido são passíveis técnicas de estatística para determinar matematicamente relações existentes entre componentes da paisagem e as preferências cênicas dos observadores [...] (PEREIRA, 2012, p. 60).

Conforme Santiago (2009) há uma estreita relação entre o desenho do espaço urbano construído e do não construído, a percepção da paisagem e a qualidade ambiental, a formação de uma imagem da cidade, da composição paisagística, identificação simbólica, e de apropriação dos espaços públicos, com a sua definição. Por isso, os espaços livres, como elementos de integração da vida urbana necessitam de valorização e qualificação.

Assim, a etapa desta pesquisa sobre a percepção se embasará em uma avaliação através do público em geral associado a fotografias, somadas às questões de uso, qualidades e opiniões referentes aos espaços livres. Este buscará informações da relação entre a paisagem e o homem, as condições atuais do espaço livre e as expectativas futuras. 


\section{O Município de Panambi/RS}

O município de Panambi está localizado na mesorregião Noroeste Rio-Grandense (Figura 1), nas coordenadas geográficas $28^{\circ} 17^{\prime} 33^{\prime \prime}$ de latitude sul e $53^{\circ} 30^{\prime} 06^{\prime \prime}$ de longitude oeste, no entroncamento entre duas das principais rodovias do estado: a BR285 e a BR-158. Sua formação deu-se a partir do final do século XIX e do início do século XX por meio dos fluxos migratórios, com a colonização predominantemente de origem alemã.

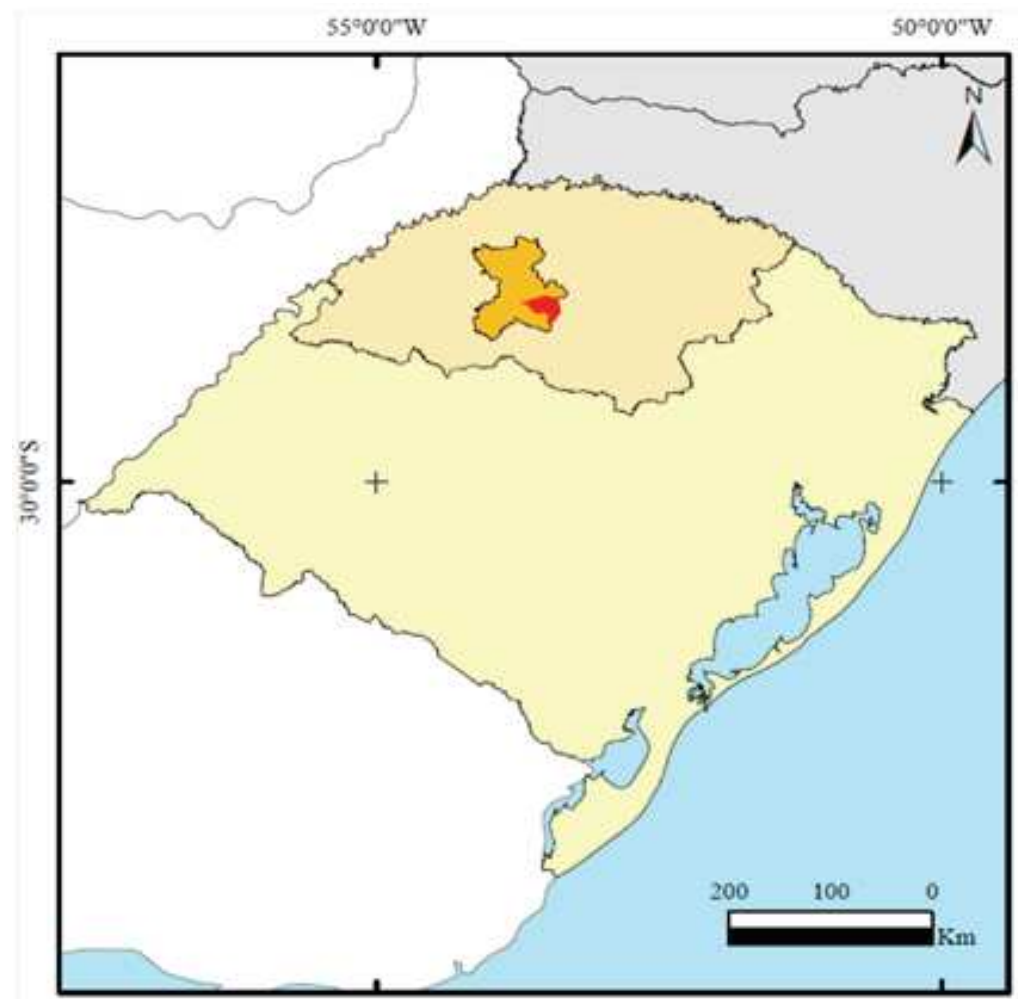

Figura 1. Localização do município de Panambi/RS.

Fonte: Elaborado pela autora na plataforma ArcGIS, 2016.
Com instalação oficial decretada em 1955, possui 38.058 habitantes (conforme o Censo Demográfico do IBGE, 2010), sendo que $90,81 \%$ de sua população está concentrada na zona urbana. O município se desenvolve na área educacional e expressivamente na área industrial, sendo um dos principais polos metal-mecânicos do Rio Grande do Sul.

Em relação ao seu traçado urbano, destaca-se que se desenvolveu conforme a topografia da cidade, caracterizada por morros e va-

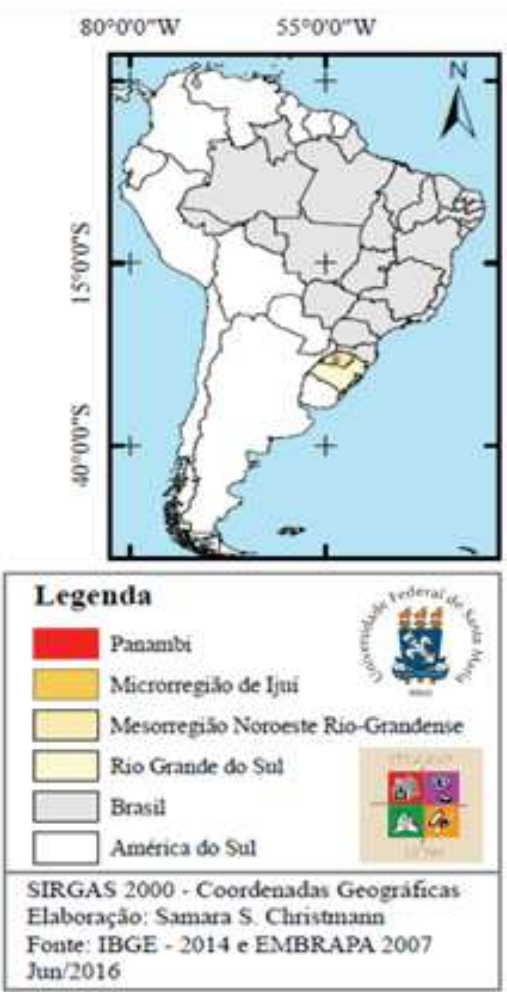

les, em uma linearidade no sentido norte-sul, com vasta visualiza- 
ção de vegetação (uma característica marcante e representativa em Panambi, tanto em espaços livres públicos como privados).

Cortando a cidade, há vários arroios e o Rio Fiúza que permeiam também o parque urbano, portanto, tem em seu território área de mata nativa - de APP (Área de Preservação Permanente). $\mathrm{Na}$ cidade há apenas um parque urbano, o Parque Municipal Rudolfo Arno Goldhardt - objeto desta pesquisa -, que se localiza no bairro Centro de Panambi/RS, juntamente com outros quatro espaços livres de lazer e recreação, as quais se compõem de praças, como se pode observar na Figura 2.
Sobre o bairro Centro, salienta-se que este é o quarto bairro mais populoso (entre os vinte e sete bairros existentes - lei de delimitação criada em 1986) de Panambi (IBGE, 2010), com 2.847 habitantes, o que representa $8,24 \%$ da população na zona urbana. Núcleo de expansão central, de intensificação da população e das atividades, enfatiza-se que este bairro tem caráter comercial, de serviços e residencial. É uma área turística com destaque para o Parque Municipal Rudolfo Arno Goldhardt (incluindo o Museu), o Rio Fiúza, a Praça $\mathrm{Eng}^{\circ}$ Walter Faulhaber, alguns templos religiosos (denominação católica, batista e luterana), dois bens culturais

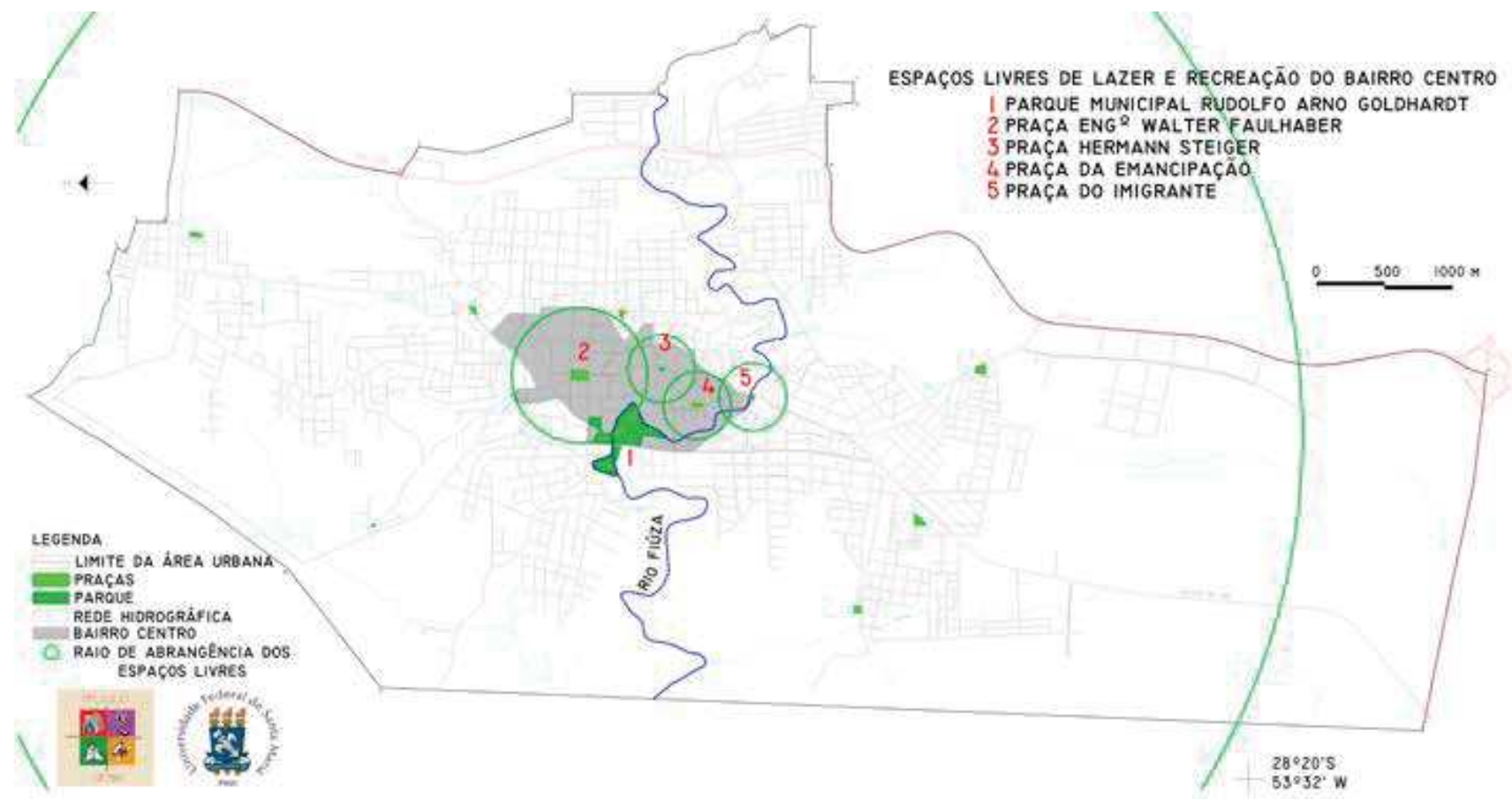

Figura 2. Localização dos espaços livres de lazer e recreação do bairro Centro de Panambi. Fonte: Adaptado do Mapa Urbano do Plano Diretor de Panambi - RS (2008). 
tombados pelo município: o Edificío Rudi Arnoldo Franke e o Castelinho, e o Monumento ao Imigrante da Praça do Imigrante.

\section{Procedimentos Metodológicos}

Este trabalho se baseou em três etapas. A etapa de análise do espaço livre buscou registrar os tipos de conectividades e acessibilidade, condicionantes físico-ambientais, infraestrutura, recursos ambientais e construídos, relação com o entorno imediato, composição paisagística, funcionalidades, tipos de uso e atividades no Parque Municipal. Para isso, foram realizadas pesquisas históricas no Museu de Panambi (MAHP) e um levantamento de campo, de caracterização do espaço livre, com base na observação da pesquisadora (através de etapas/tópicos qualitativos desenvolvidos por Pippi et al., 2011).

Em seguida submeteu-se o trabalho à preferência da paisagem que liga os aspectos empíricos e sensoriais, o enfoque científico, e quali-quantitativo (atribuições subjetivas de significado às paisagens e mensuração de fenômenos, com coleta de dados numéricos e testes estatísticos).

O estudo da preferência da paisagem do Parque Municipal Rudolfo Arno Goldhardt se embasou na coleta de dados a campo e com o uso de fotografias, em que uma valoração é determinada por observadores através visualização de substitutos da paisagem (imagens que simulam o ambiente real), tais como as fotografias (MARENZI, 1996; PEREIRA, 2012). Assim, admitiram-se os mais diferentes representantes da sociedade em geral para realizarem a sua valoração.

Tendo-se isso em vista, foram registradas inúmeras fotografias diurnas nas mais diversas possibilidades e perspectivas para cada categoria de paisagem. Salienta-se que elas foram obtidas nos mesmos horários e com condições climáticas (céu limpo) semelhantes para o Parque, nos dias 03/11 e 07/11/2017, das 09h às $12 \mathrm{~h}$.

Portanto, devido à diversidade de atividades no Parque, registraram-se 241 fotografias, e destas foram selecionadas catorze fotografias, as quais foram subdivididas em dez categorias (atividades/setores/usos do parque): acesso; edificações principais (2 subcategorias: ginásio; e salão de eventos); áreas esportivas (4 subcategorias: área central de esporte e recreação; gramado esportivo; área de exercícios e campos esportivos; e a pista de skate); anfiteatro; playground; academia ao ar livre; Casa das Etnias; trilhas; espaço gourmet; rio Fiúza (que interliga as áreas do parque).

Nos registros fotográficos utilizou-se uma câmera Kodak de 14 megapixels, e a sua impressão, para manusear com os entrevistados, possuía qualidade em papel foto, em tamanho $10 \times 15 \mathrm{~cm}$.

Para que os observadores atribuíssem a sua valoração perceptiva de preferência, elaborou-se uma classificação (Figura 3) para ordenar as fotografias da paisagem, em que cada respondente atribuiu valor de um a cinco para as imagens (Classes de 1 a 5).

$\begin{array}{cc}\text { Classe } 5 & \text { Preferência Muito Alta } \\ \text { Classe } 4 & \text { Preferência Alta } \\ \text { Classe } 3 & \text { Preferência Média } \\ \text { Classe } 2 & \text { Preferência Baixa } \\ \text { Classe } 1 & \text { Preferência Muito Baixa }\end{array}$

Figura 3. Classes de Preferência da Paisagem.

Fonte: Elaborado pela autora, com base em Kaplan (1985), Marenzi (1996) e Pereira (2012)

Associado ao estudo perceptivo da preferência da paisagem houve uma continuação do questionário (APÊNDICE A), que solicitou informações sobre o perfil do usuário entrevistado, e outras questões para apreender a opinião particular sobre a paisagem em questão.

Esse questionário foi organizado a partir de trabalhos já realizados com metodologias quantitativas e qualitativas, de interação com os usuários, de análise de espaços livres intraurbanos públicos, pelo Grupo de Pesquisa Quapá-SEL do Núcleo Santa Ma- 
ria, do laboratório PARQ - Paisagismo e Arquitetura do curso de Arquitetura e Urbanismo da UFSM (PIPPI et. al, 2015)

Conforme Pippi et al. (2015), o objetivo da aplicação de tal pesquisa de interação com os usuários de abordagem quali-quantitativa, com perguntas abertas e fechadas, concebe o registro das informações de quem são os entrevistados; se estes utilizam os ambientes dos espaços livres e como se relacionam com suas paisagens; quais são as atividades desenvolvidas; e como as características físico-ambientais afetam o uso e apropriação do espaço. Portanto, a aplicação desse instrumento seguiu a anotação de variáveis sociais (perfil dos usuários, frequência de uso, tipo de uso/atividade, relação com o espaço).

A etapa qualitativa do instrumento consistiu em perguntas abertas que contribuíram com a compreensão de "motivações emoções, percepções, aspectos positivos, aspectos negativos, atividades/padrões de uso e ambientes preferenciais" (PIPPI et al., 2015 , p. 152) e sugestões para a paisagem. Ali, as questões foram abordadas com o objetivo de averiguar a satisfação, desejos, vínculos e identidade com o espaço livre. E a parte quantitativa consistiu em perguntas fechadas com questões de múltipla escolha e linguagem simplificada, que coletou informações como do tipo de atividades e uso, intensidade e frequência do uso na paisagem, além de informações do perfil dos entrevistados.

Assim, adotou-se que para cada categoria de fotografias estipuladas do espaço livre, haveriam 10 questionários de amostra, que resultou em 100 questionários, aplicados do início do mês de novembro de 2017 até a metade do mês de dezembro de 2017 Deste modo, a coleta dos dados foi aplicada praticamente em cidadãos que estivessem em outros locais (que não a paisagem em estudo), como instituições, comércios, residências e serviços do entorno, mas que utilizassem a paisagem referida ao menos uma vez ao ano.

Com esses dados coletados, a pesquisa prosseguiu com a sua análise: leitura dos questionários; organização, categorização e tabulação dos dados; e redação dos dados obtidos. Por meio de médias efetuadas de cada fotografia, e todas as demais questões sociais ou sobre a paisagem, foi elaborada uma matriz de dados em uma planilha eletrônica do Excel, o que permitiu a elaboração de gráficos, tabelas estatísticas e sua descrição, para o estabelecimento dos resultados e discussões.

Objetivou-se com essa análise de dados, conhecer a preferência pelos ambientes/lugares da paisagem do espaço livre (quais ambientes são os mais ou menos preferidos/agradáveis/usuais), quais as atividades mais desempenhadas ou preferíveis no espaço livre, e quais as considerações/adaptações ou melhorias necessárias/ opiniões sobre as categorias de paisagem do espaço livre, ou a paisagem em si.

Desta forma, a última etapa do trabalho consistiu em contribuir com medidas que subsidiassem a gestão e planejamento territorial de futuras intervenções e manutenção do parque. Consideraram-se seus conflitos e fragilidades, e as potencialidades para investimento, por meio de recomendações para a paisagem, com base na análise do espaço livre, e da coleta de dados com os entrevistados.

\section{O Parque Municipal Rudolfo Arno GoldhARDT}

5.1 Características e análise do Parque Rudolfo Arno GoLDHARDT

O Parque Municipal Rudolfo Arno Goldhardt é o parque urbano de Panambi, conhecido também como "ginasião", que abrange uma grande parte da área central do município, não apenas o bairro Centro, mas também uma porção do Bairro Parque Moinho Velho (Área 2 e Área 3 da Figura 4). Seu território é estruturado por várias áreas que são cortadas e margeadas pelo rio Fiúza ou pelo seu afluente, o Arroio Moinho, e contempla uma relação harmoniosa com o sistema biofísico, intensa vegetação arbórea nativa e exótica (e demais, como palmeiras, arbustos, trepadeiras, herbáceas e forrações) com estado de conservação bom e também modificado, como se observa na Figura 5. Possui uma área de aproximadamente $9 \mathrm{ha}$, em que suas extensões fo- 


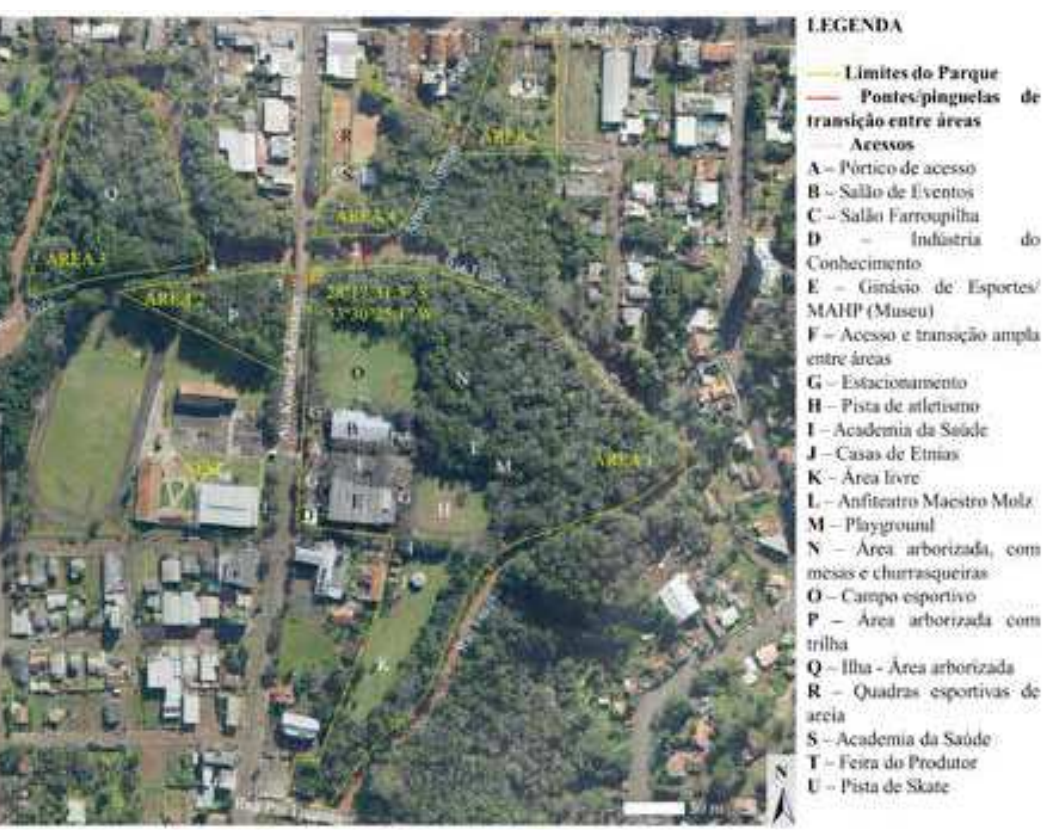

142

Figura 4. Parque Rudolfo Arno Goldhardt - Areas e identificação. Fonte: Adaptação pela autora da fotografia cedida pelo MAHP - Panambi.

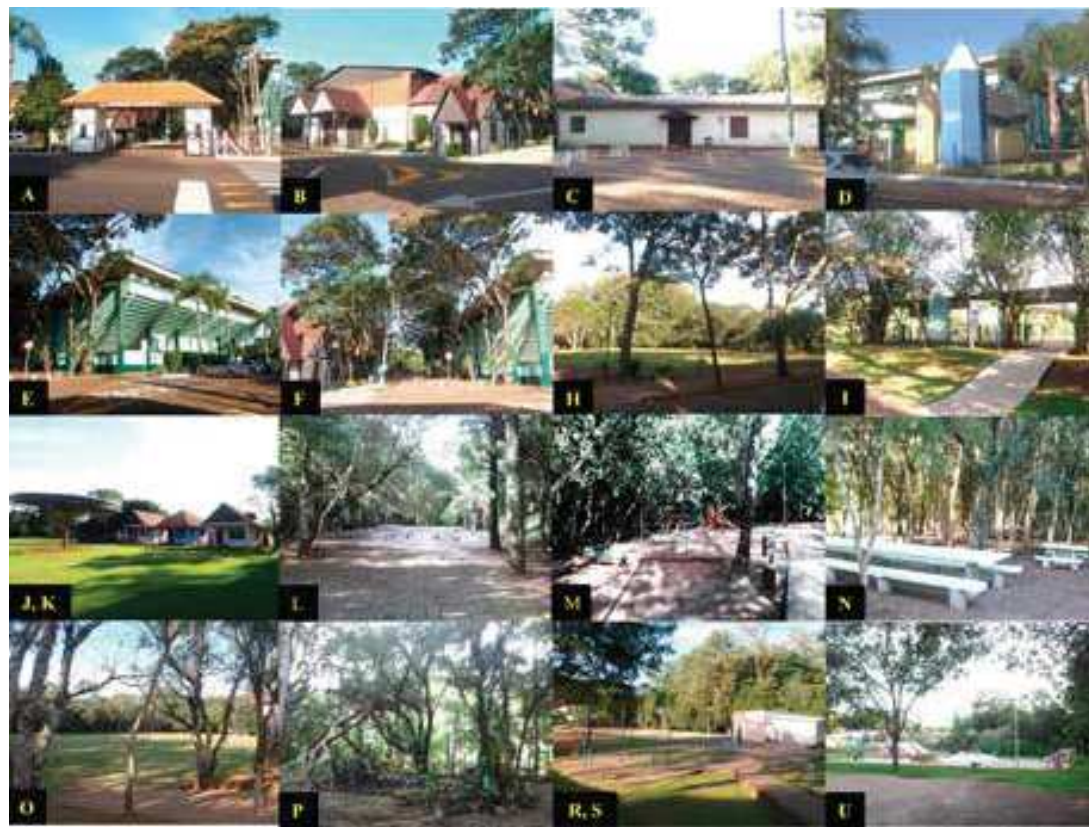

Figura 5. Fotografias de alguns espaços do Parque Municipal Rudolfo Arno Goldhardt. Legenda conforme Figura 4. Fonte: acervo da autora, fevereiro e março de 2017. ram sendo adquiridas, somadas e consideradas como de utilidade pública ao longo dos anos.

Paisagem de grande relevância ambiental, infraestrutura verde, estética, conservação dos recursos naturais, lazer/recreação/esportes, cultura, circulação e com grande potencial para educação (o qual já é disseminado por escolas), é utilizada por todas as faixas etárias, animais domésticos e também para muitas atrações e encontros locais/regionais.

O acesso principal se localiza na Área 1, e se dá pela Avenida Konrad Adenauer, em um pórtico de estilo arquitetônico germânico, construído no ano de 2004. Há outro acesso na mesma avenida - para as quadras de areia e academia -, e um na Rua
Andrade Neves - pela Feira do Produtor, e outras trilhas de ligação entre as áreas vegetadas. Ambas as vias são arteriais de fluxo intenso e asfaltadas. Na Área 1 e 2 o Parque tem área de funcionamento das 6:00h às 22:00h. As áreas 4 e 5 permanecem abertas e a área 3 não permite acesso atualmente (ponte constantemente destruída pela dinâmica do Rio Fiúza).

A Área 5, conhecida pelo terreno da Feira do Produtor (conjunto arquitetônico inspirado em características germânicas que possui de terça a sábado a exposição por feirantes locais), é utilizada como local de transição para as demais áreas do Parque, que cria um vínculo importante das áreas de preservação com as atividades esportivas e de lazer. Além disso, essa área possui uma pista de skate, que foi inaugurada no ano de 2013. 
Em agosto de 1974 a Lei Municipal n³73/74 autorizou o Executivo Municipal a efetuar a compra da área inicial e formar o orçamento para a construção do Ginásio Municipal de Esportes (Pavilhão de Esportes). Sua conclusão ocorreu no ano de 1981، e ali se desenvolvem competições esportivas municipais e jogos semanais. Assim, o Parque foi denominado Rudolfo Arno Goldhardt pela Lei $n^{\circ} 1.434$ apenas no ano de 1995, e é mantido pela Prefeitura Municipal.

Em relação à ilha cercada pelo rio Fiúza (Área 3), não possuía esse caráter de ilha até o ano de 1986, em que foi alterada a sua dinâmica e aberto o canal entre a Área 2 e a 3 para realizar um melhor escoamento e vazão do rio. Já a área 2 é destinada somente a trilhas, conservação e contemplação da paisagem.

Sobre isso, de acordo com Macedo (2002), no Brasil, desde os anos 70 se torna comum o aproveitamento de remanescentes de matas nativas para a implantação de parques urbanos. Assim percebe-se o valor cênico e ambiental como objeto dos projetos de preservação e conservação para o aproveitamento para as atividades recreativas. Objetivo este que estava em planejamento com as compras de terra para implantação do Parque.

Entre as áreas que são cortadas pelo rio Fiúza, há dois acessos em passarelas sobre o rio, construídas entre 2001 e 2004. Uma delas, a Pinguela 2 (Conforme Figura 4) já foi muitas vezes reconstruída, devido à intensidade, força e dinâmica do rio Fiúza, principalmente em momentos de enchentes, o que torna o parque uma região inundável e vulnerável. Nestes momentos, também, boa parte do parque, próxima às margens do rio, são inundadas e ficam lameadas, motivo que atrai ou repele os seus usuários.

Dentre o mobiliário urbano se encontram bancos, telefones pú blicos, poucas placas informativas, bebedouros, brinquedos, lixeiras, esculturas, sinalização, cercas e fechamentos em partes dos limites territoriais, e mesas em um estado regular de conservação. A pavimentação é predominante de concreto e paralelepípedos de concreto, além de haverem trilhas naturais sobre o solo.

No Parque Municipal, destaca-se uma trilha, com extensão de mais de 1.000 metros, que em seu trecho inicial (aprox. 600 me- tros) foi delimitada com cascalho até 1992 e concretada no ano de 1997, período em que se instalaram também as luminárias ao longo do caminho. Atualmente, essa trilha atrai uma grande quantidade de pessoas para realizarem suas caminhadas, cooper e passeios entre a vegetação e margeando o rio Fiúza.

Entre os anos de 1994 e 1995 foi realizada a construção do Salão Farroupilha que se tornou uma sede para eventos diversos. Ao final de 2017, foi interditado, devido às condições da cobertura, e está em trâmite para reconstrução. Aos fundos dessa edificação, há a área de banheiros e também churrasqueiras cobertas, que se encontram em condições mais precárias de manutenção.

É no ano de 1995 que o Museu e Arquivo Histórico Professor Hermann Wegermann se instala em uma parte superior do prédio do Ginásio de Esportes. Sem acessibilidade adequada para todo o público (pois se localiza no segundo pavimento, com acesso por uma escada metálica), o MAHP surgiu através da iniciativa de um grupo de professores do Colégio Evangélico Panambi (CEP) em 1968. Ele pretende manter viva na memória de Panambi o seu contexto econômico, cultural, religioso, social e politico. Com isso, é uma grande fonte de pesquisa e local de muita visitação no Parque.

Também no ano de 1995 ocorre a inauguração do Anfiteatro Maestro Molz, que permite apresentações teatrais e musicais ao ar livre, porém, é pouco utilizado. Já no Salão de Eventos, construído e ampliado em partes (com conclusão em 1995), ocorrem as mais diversas atrações e eventos municipais e locacionais, e também sedia o DESTUR, Departamento de Turismo. E o Departamento de Esportes e Lazer, localiza-se aos fundos do Ginásio.

Neste sentido, o município, que valoriza a música desde seu tempo de Colônia, também institucionalizou eventos em âmbito municipal, o Festival da Canção Sacra; o Moinho da Canção Gaúcha; e o Evento da Oktoberfest - considerado Patrimônio Cultural de Panambi-, que são referências de eventos realizados no parque. Entre outras atividades que constam no Calendário de Eventos do Município de Panambi, que são realizadas no parque citamse: Encontro de Corais, Cultos Ecumênicos, Baile do Chopp, Mos- 
tra de Trabalhos das diferentes Escolas, Feira do Livro, Feira do Artesanato, Congressos Nacionais e Internacionais, Encontro da Terceira Idade, etc.

No ano de 2002 é adquirida a área sobre a qual se construíram edificações com características arquitetônicas próprias de etnias (gaúcha, germânica, holandesa, portuguesa, italiana) que compõem o denominado Condomínio Parque das Etnias e Entidades Sociais. Sobre este conjunto, afirma-se que é pouco utilizado e suas construções não foram devidamente concluídas.

Sobre as Academias de Saúde, enfatiza-se que uma está localizada próxima às Casas de Etnias e foi instalada em 2008, e o outro conjunto está próximo das quadras de areia e foi construído em 2011, e o uso se dá de forma intensa pelo público.

O parque urbano sedia a Feira do Livro anual pelo mês de agosto/ setembro. Com esta característica, em 2014 realizou-se a inauguração da conhecida Indústria do Conhecimento, construção com características arquitetônicas inspiradas em livros e aquisição de ceria realizada entre a Prefeitura Municipal (por parte da SMEC Secretaria Municipal de Educação e Cultura) e o SESI. O local atra e procura instigar com leitura e conhecimento principalmente crianças e adolescentes.

Além disso, têm-se no Parque outras atividades ativas de lazer, recreação e esporte, como o playground, campo esportivo, pista de atletismo, e atividades passivas diversas áreas com mesas, churrasqueiras e espaços para convívio, almoços familiares, e reuniões da população.

Com tudo isso, se percebe que este parque apresenta várias alterações antrópicas, as quais foram realizadas a fim de proporcionar aos panambienses uma área de lazer, cultura, esporte, recreação, de contemplação do Rio Fiúza e do sistema biofísico que o contorna, e ao mesmo tempo conservar suas margens e paisagem natural. É por todas essas características que pode se afirmar que o Parque Municipal Rudolfo Arno Goldhardt é um espaço livre de grande atratividade para a população local e regional.
5.2 Preferência da Paisagem do Parque

Os cem questionários para o Parque Municipal Rudolfo Arno Goldhardt foram aplicados em sua maioria em áreas comerciais, institucionais e de serviços. Assim, de acordo com a Figura 6, obteve-se uma coleta semelhante nas categorias de gênero (feminino:51; masculino:49), entre as faixas etárias, e na média entre o gênero e as faixas etárias. Na categoria escolaridade prevaleceram os índices de escolaridade do ensino fundamental (42,16\%), e do médio completo $(19,61 \%)$.

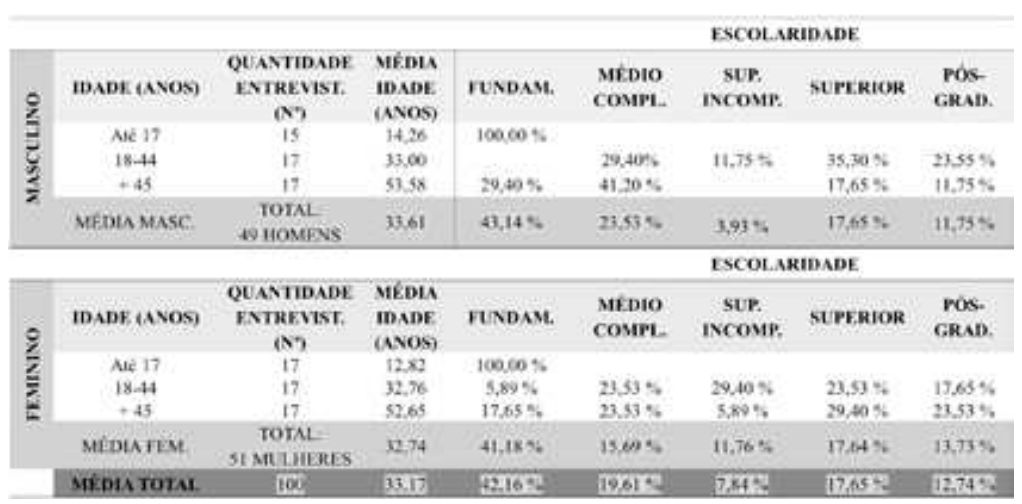

Figura 6. Relação do perfil dos entrevistados do Parque Fonte: Elaborado pela autora, 2018.

Na valoração de preferência da paisagem do parque, estabeleceu-se um ranking (Figura 7) com a média geral total de valoração que as catorze fotografias obtiveram. Abaixo de cada foto se encontra a média de valoração geral, e as médias diferenciadas entre os gêneros (em cada lado da média geral, distinta por cores).

Assim, dentre as fotos do ranking, a primeira revela a área central de esporte e recreação, local que reúne maior número de usuários em todo o parque, e que é muito utilizado pelas famílias, além de possuir visual estético agradável. Na sequência, as quatro fotografias de preferência média são de áreas esportivas 


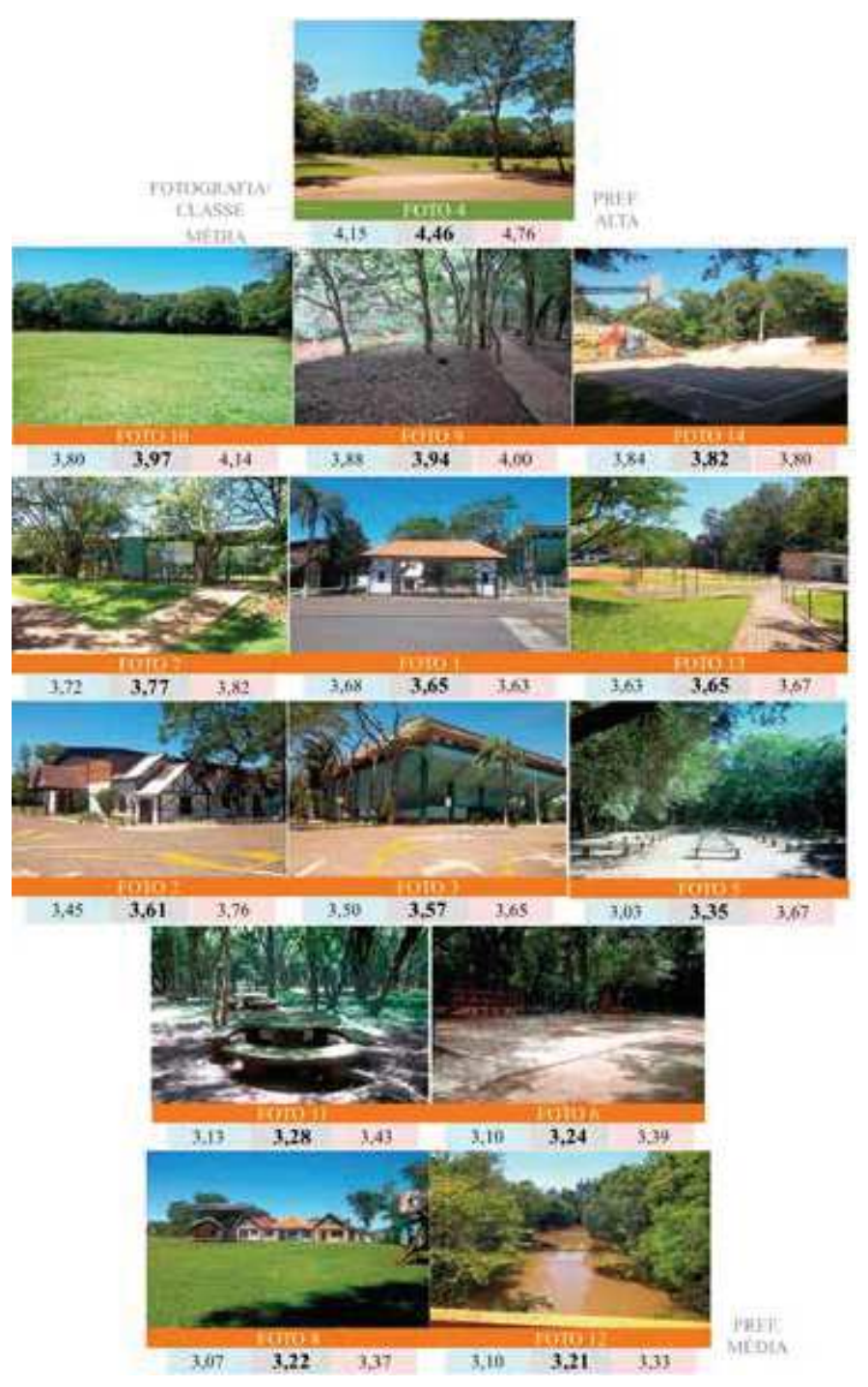

e de exercícios: o gramado esportivo, a trilha, a pista de skate e a academia ao ar livre. O segundo conjunto de preferência média contém fotografias com maior abrangência de edificações, a exemplo do pórtico de acesso, uma academia (da área de exercícios e campos esportivos), o Salão de Eventos e o Ginásio. Em seguida, o terceiro conjunto demonstra fotografias com áreas mais fechadas e sombreadas: o anfiteatro, o espaço gourmet e o playground.

Por fim, entre as últimas fotos valoradas estão o gramado com a Casa das Etnias (em que os entrevistados pouco utilizam, reparam ou vêem sentido de existência) e o Rio Fiúza, que corta as diversas áreas do Parque Municipal (e que foi lembrada a péssima estética causada pelo lixo nas margens, e as pinguelas, que seguidamente estão interrompidas). Nota-se ainda, que entre os gêneros obteve-se maior concordância nas fotos 14, 1 e 3, que representa a pista de skate, o acesso principal e uma das áreas de exercícios e esportes.

Com tudo isso, elaborou-se também um mapa (Figura 8) das áreas de maior preferência dos cidadãos pelas categorias/subcategorias da paisagem a partir das Classes de Preferências atribuídas, representando as vistas ou áreas valorizadas pelos usuários.

Ao seguir a análise dos dados, dispõe-se na Figura 9 uma síntese com as demais e principais informações coletadas do questionário aplicado no parque - inclusive as principais recomendações,

Figura 7. Ranking de Preferência da Paisagem.

Fonte: Elaborado pela autora, 2018. 


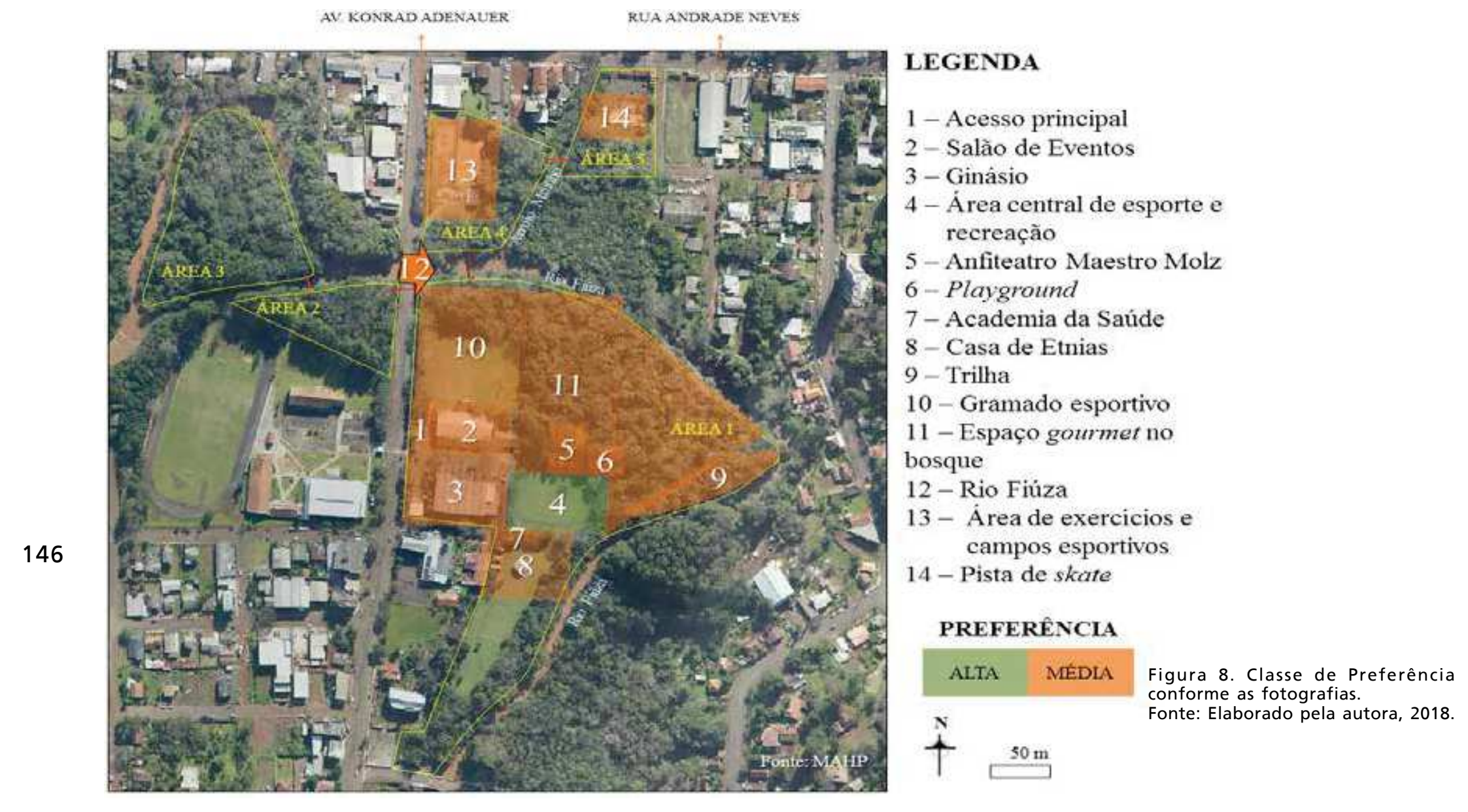

que se encontram descritas abaixo. O conjunto de dados completo pode ser visualizado no APÊNDICE B.

A partir dos dados levantados sobre o Parque Municipal Rudolfo Arno Goldhardt, percebe-se que devido ao bem-estar e tranquilidade e diversas possibilidades de atividades que este território oferece, atrai o público em massa, principalmente entre família e amigos, aos finais de semana, e por um longo período de tempo, 
Figura 9. Síntese de informações do Parque. Fonte: Elaborado pela autora, 2018.

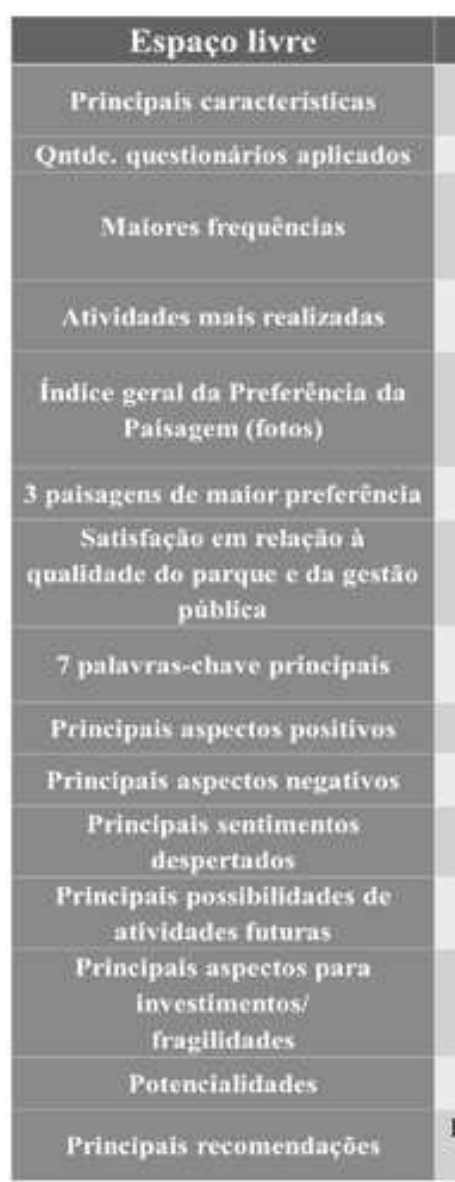

Parque Municipal Rudolfo Arno Goldhardt
Parque urbano de aprox. 10 ha, estruturado por vairias áreas que são margeadas pelo rio Fiüza ou afluente 100

1-3x por semana/1-3x por mês; finais de semana; com familia $e$ amigos; das $17-$ 20h:

$$
\text { de } 1-2 \mathrm{~h} \text { de permanência }
$$

Apreciação, contato com natureza, observaçōes (paisagem, fauna, pessoas), interaçâo social, eventos, exercícios, e refeiçōes

$$
\text { (média masculina: } 3,50 \text { ) }
$$$$
\text { (média feminina 3.74) }
$$

Área central de esporte e recreaçjo; gramado esportivo; trilha

\section{Média-alta}

Natureza; acoihedor; bonito; exercicios; diversão; tranquilidade; lazer

Natureza; ativ/exercicios; trilha; quadras/espontes; convivio

Banheiros; vandalismo; sujeira; estrutura fisica; mobiliário urbano

Bem-estar, tranquilidade; felicidade; satisfação

Espaço gourmet; pista de ciclismo

Estrutura fisica; mobiliário urbano; falta de regulamentação de uso; Manutençăo/limpeza

Esportivo, recreativo, turistico; educativo e de conservação da paisagem

Pista de ciclismo; ảrea gourmet; playground; educação ambiental; estrutura física c mobiliảrio; manutençảo/limpeza para desfrutar da paisagem, ter maior contato com a natureza e interação social, para lazer e recreação, praticar exercícios e esportes, e também participar em eventos.

As palavras-chave definidas pelos entrevistados só confirmaram esses usos e as preferências do parque. A Preferência da Paisagem manifestou por meio das fotografias que os questionados atribuíram uma valoração mais alta para os ambientes esportivos, seguido pelas edificações, e os demais locais que estão desvalorizados em sua estrutura e uso. E dessas fotografias, as eleitas como mais representativas do parque também estão algumas das áreas de exercícios, esportes e as construções singulares e de intenso uso, como o ginásio, e o Salão de Eventos.

Também foram salientadas algumas potencialidades tanto na questão de sugestões de atividades que podem vir a ser reali- 
zadas no parque, como na de aspectos que necessitam de investimentos. Vale atentar para o potencial de uso esportivo, recreativo, educativo (Museu, Rio e biodiversidade), e de conservação da paisagem (recursos naturais).

Pode se mencionar como potencial a implantação de um bicicletário e uma pista/trilha de ciclismo, visto que não há uma pista destinada só ao ciclismo - o que gera conflitos entre os usuários ciclistas e os pedestres -, e existe área territorial para sua efetivação, tal como nas proximidades da Casa de Etnias, ou na borda da trilha existente. Assim, cada atividade/esporte teria uma trilha exclusiva.

Também, há potencial na locação de um espaço gourmet, destinado a servir lanches e bebidas básicas, uma vez que houve uma porcentagem considerável dos respondentes que realiza refeições no parque, e pelo tempo elevado (entre uma e mais de três horas) de permanência dos usuários. Poderia ser utilizada a Casa de Etnias, em que foi sugerida atribuição de uso, e/ou a área próxima à pista de Skate.

Salienta-se também a necessidade de manter, renovar e ampliar as opções de brinquedos para o playground, pois o parque é uma referência de diversão para as crianças e se encontra em dimensões limitadas. Além disso, é interessante uma identificação com instrução de idade para os brinquedos, e barreiras delimitadoras de segurança entre os mesmos.

Atividades e exercícios de aventura também foram lembrados, tais como a escalada (começou a ser instalada no mês de fevereiro de 2018 em uma das paredes do ginásio), arvorismo/ arborismo, e tirolesa. As opções necessitam de acompanhamento profissional, mas tem potencial no que tange ao declive em direção ao rio, e à existência de árvores altas e em diversidade, o que se poderia agregar para um conhecimento sobre a fauna e flora.

Outra ideia relevante é a possibilidade de haver nas trilhas já existentes uma identificação (e instrução) sobre a biodiversidade presente no local, e formas de como conservar/preservar. Com isso, pensa-se no aproveitamento dos exemplares naturais, como meio de valorizar, conservar o ambiente, e instigar o lúdico dos usuários do espaço livre. Outros instrumentos para a educação ambiental também podem ser ponderados em relação ao Rio Fiúza, pois atribui visual cênico e é a fonte de abastecimento de água de Panambi.

Somando-se a isso, observou-se que a satisfação quanto à qualidade e a gestão neste espaço livre são boas, e muitos aspectos positivos se manifestam neste sentido, apreciando a conservação da natureza, e os vários usos possíveis. Porém, os aspectos negativos e as sugestões para investimento denunciam os pontos frágeis do parque.

Entre essas fragilidades encontram-se principalmente as condições de infraestrutura (estrutura física) e do mobiliário - estruturas básicas e importantes para o conforto público. Reivindicou-se do mobiliário: mais bancos, lixeiras e iluminação espalhados pelo parque; bebedouros nas demais áreas; e limpeza das mesas/ bancos do espaço gourmet (cobertas por musgos e vegetação). Também, ações como a limpeza, higiene e manutenção dos banheiros, que é básica para definir o tempo de permanência na paisagem, e é considerável na satisfação dos usuários.

Nas manifestações em relação às demais construções, os interrogados indagaram a manutenção, pintura e qualidade acústica (nos eventos), do Salão de Eventos e Ginásio, e a acessibilidade do Museu - que atualmente é por escadas e sem elevador. Ainda mais, a acessibilidade às pessoas com deficiência é pouco garantida (sem piso tátil, instruções, pavimentação).

O espaço livre está identificado externamente com uma das placas de turismo, apenas próximo do acesso principal. Por isso, sugere-se implantar uma placa de identificação externa visível, e até, identificações internas (com especificações) das atividades e ambientes disponíveis.

Quanto às atividades esportivas, lembrou-se das condições das quadras, goleiras (sem rede), da necessidade de marcação no campo esportivo e de redes nas quadras de vôlei. Nas áreas de 
exercícios foi indicado alargar a trilha (há aprox. 1,50m de largura), pelo fato da dificuldade de fluxo em dias de intenso uso - que é compartilhado com que caminha, corre, pedala, e utiliza outros brinquedos. Porém, como descrito no parágrafo anterior, com a identificação de usos permitidos e fiscalização, poderá ser solucionado.

Ressalta-se ainda a construção de passarelas/pinguelas mais resistentes às ações das águas, pelo fato de que são muito utilizadas pelos usuários para transitar entre as diversas áreas do parque. Outra preocupação é com um melhor condicionamento da entrada de veículos e pedestres, e com relação ao número das poucas vagas no estacionamento de um parque tão grande.

Tais comentários, indicações e recomendações pode vir a agrega qualidade ao Parque Municipal, se a gestão pública conseguir mobilizar, valorizar suas potencialidades e atender aos anseios e insatisfação de tantos cidadãos. Também, o espaço livre pode vir a se tornar uma referência de uso para a região, visto que não há parques urbanos nos municípios limítrofes.

\section{Considerações Finais}

Diante da pesquisa realizada, obteve-se um conjunto grande de informações sobre as características e percepções do Parque Municipal Rudolfo Arno Goldhardt, que integra um sistema de espaços livres do bairro Centro. Assim, notou-se que o Parque Municipal é uma paisagem de grande uso no município de $\mathrm{Pa}$ nambi/RS. Também, sentiu-se identidade/apropriação em relação aos entrevistados, durante as pesquisas de campo.

Tal estudo teve um tempo extenso de aplicação dos cem questionários, porém, não houve grandes dificuldades no seu decorrer Salienta-se que praticamente todos os cidadãos que foram abordados concordaram em colaborar com o estudo.

Além disso, quanto ao estudo de percepção empírico, destaca-se novamente a subjetividade que influencia nos dados coletados Ou seja, a mesma pesquisa, em uma estação diferente, em uma época/tempo diferente, com pessoas diferentes poderia ou não proceder em diferenciados conjuntos de dados e investimentos recomendados.

Contudo, compreendeu-se por meio desse processo interpretativo e valorativo da paisagem, como a sociedade tem utilizado o espaço livre e como o reconhece. Inclusive, como a arquitetura paisagística pode vir a ser alterada e qualificada através dos dados coletados, por meio de recomendações da população entrevistada.

Com isto posto, acredita-se que o método de pesquisa de Preferência da Paisagem com os questionários, foi de grande valia ao acrescentar à pesquisa de Pippi et al (2015) a valoração de fotografias locais por classes de preferência. Pois, ao se privilegiar a experiência sensorial visual no manuseio de fotografias, podemse conseguir resultados muito próximos da realidade (BERNALDEZ, 1985). Também, contribui ao inserir o nível de satisfação dos usuários em relação à qualidade e gestão da paisagem, e sobre os investimentos que os cidadãos consideram relevantes para a paisagem.

Em vista disso, acredita-se que o levantamento/diagnóstico do parque buscou reconhecer os recursos existentes e usos que são atribuídos à paisagem, e formou uma composição mais urgente e relevante de recomendações, com o propósito de contribuir para a gestão da paisagem, nos âmbitos de valorizar as potencialidades locais, investir nas fragilidades, possibilitar melhor apropriação e identidade e promover a conservação ambiental, e direcioná-los em grande parte conforme as necessidades dos usuários.

Portanto, espera-se que as recomendações e sugestões possam ser ponderadas pela gestão pública, e almeja-se que o parque, bem como outros espaços livres cumpram a sua função na cidade e mantenham equilíbrio no meio urbano, com conforto e qualidade de vida para os cidadãos. Neste sentido, pondera-se que este procedimento metodológico pode ser replicado em outros espaços livres, respeitando e acrescentando também outras questões inerentes a cada área. 


\section{REFERÊNCIAS BIBLIOGRÁFICAS}

ANDRÉ, Pierre; SCHWARZ, Maria L.; SEVEGNANI, Lucia. Preferências e valores para com as paisagens da Mata Atlântica: uma comparação segundo idade e o gênero. Revista Caminhos ufu.br/index.php/caminhosdegeografia/article/viewFile/15797/8930 >. Acesso em: 20 jan. 2017. BERNÁLDEZ, Fernando G. Invitación a la ecologia humana: la adaptación afectiva al entorno. Madrid: Tecnos, 1985

BIONDI, Daniela; KOZERA, Carina; VIEIRA, Carolina H. S. D. Preferência visual de paisagen do Parque Municipal do Passaúna, Curitiba, PR. Revista Paisagem Ambiente, n.24, p. 421-430

BOLÓS, Maria. Manual de ciencia del paisage: Teoría, métodos y aplicaciones. Barcelona: Masson S. A., 1992.

KAPLAN, Rachel. The analysis of perception via preference: a strategy for studying how the environment is experienced. Lanscape Planning, Amsterdam, v. 12, p. 161-176, 1985. Disponível em: < https://deepblue.lib.umich.edu/bitstream/handle/2027.42/25604/0000151.pdf?1Th

MACEDO, Silvio S. Espaços livres. Paisagem e Ambiente, São Paulo, n. 7, p. 15-56, jun. 1995. MACEDO, Silvio. S; ROBBA, Fábio. Praças Brasileiras. São Paulo: Edusp, 2002.

150 MACEDO, Silvio S.; SAKATA, Francine G. Parques Urbanos no Brasil. 3. ed. São Paulo: Edusp

MACEDO, Silvio S. et al. Considerações preliminares sobre o sistema de espaços livres e a constituiçăo da esfera pública no Brasil. In: ANDRADE, Rubens de; SCHLEE, Mônica B.; TANGARI, Vera R. (org.). Sistema de espaços livres: o cotidiano, apropriação e ausências. Rio de Janeiro: Universidade Federal do Rio de Janeiro, Faculdade de Arquitetura e Urbanismo, Pós-Graduação em Arquitetura, 2009. P. 60-83.

MAGNOLI, Miranda M. E. M. Espaços livres e urbanização: Uma introdução a aspectos da paisagem metropolitana. 1982. Tese (Livre-docência) - Faculdade de Arquitetura e Urbanismo, Universidade de São Paulo, São Paulo, 1982.

MASCARÓ, Juan L. (org.) Infra-estrutura da paisagem. Porto Alegre: Masquatro Editora, 2008. PEREIRA, Frank G. O pampa como bioma e paisagem cultural: um estudo de percepção ambiental e preferência paisagística. 2012. Dissertação (Mestrado em Geografia) - Universidade

Plano Diretor Participativo de Desenvolvimento Municipal de Panambi - RS. 2008.

MARENZI, Rosemeri C. Estudo da valoração da paisagem e preferências paisagísticas no mu nicípio de Penha - SC. Dissertação (Mestrado em Ciências Florestais), Universidade Federa do Paraná, Curitiba, 1996

Museu e Arquivo Histórico Professor Hermann Wegermann - MAHP. Panambi: De Colônia a Município. 2 ed. Panambi: Bühring Ltda., 2014.

PIPPI, Luis G. A. et al. A dinâmica dos espaços livres intra-urbanos da cidade de Santa Maria -RS. Paisagem e Ambiente, São Paulo, n. 29, p. 189-226, 2011. Disponível em: < http://www. revistas.usp.br/paam/article/view/85315 >. Acesso em: 27 set. 2016.
PIPPI, Luis G. A. et al. Utilização de multimétodos de caracterização e análise da paisagem e dos espaços livres intraurbanos de Santa Maria - RS. Paisagem e Ambiente, São Paulo, $\mathrm{n}$.

RODRIGUEZ, José M. M.; SILVA, Edson V. A. Planejamento e Gestão Ambiental: subsídios da geoecologia das paisagens e da teoria geossistêmica. Fortaleza: Ediç̧̃es UFC, 2013.

SANTIAGO, Alina G. As formas de uso no sistema de espaços livres: evento e cotidiano no espaço central de Florianópolis. In: ANDRADE, Rubens de; SCHLEE, Mônica B.; TÂNGARI, Vera R. (Or.). Sistema de espaços lives. o cotidiano, apropriaçăo e ausências. Rio de Janeiro. Uniem Arquitetura, 2009. P. 228-239.

TUAN, Y. F. Topofilia: Um estudo da percepção, atitudes e valores do meio ambiente. São Paulo: Difel, 1980.

Samara Simon Christmann

Universidade Federal de Santa Maria, Programa de Pós-Graduação em Geografia.

Rua Luiz Felipe Schmidt, 123. CEP: 98280-000, Panambi, RS, Brasil.

CV: http://lattes.cnpq.br/1715281920824293

E-mail: samara.s.c@hotmail.com

Eliane Maria Foleto

Universidade Federal de Santa Maria, Programa de Pós-Graduação em Geografia.

Campus da Universidade Federal de Santa Maria, Prédio 17/sala 1132. CEP: 97105-900, Santa Maria, RS, Brasil.

CV: http://lattes.cnpq.br/8174927772410793

Orcid: http://orcid.org/0000-0003-22-5-7801

E-mail: efoleto@gmail.com

\section{Agradecimentos}

A autora agradece a Coordenação de Aperfeiçoamento de Pessoal de Nível Superior (CAPES) pelo apoio financeiro.

Nota do editor

Revisão do texto: Autoras

Revisão do Inglês: Hugo Karr

Aprovado em : 26/01/2019 